\title{
Exploratory and confirmatory factorial analysis of the OHIP-Edent instrument
}

\section{Anna Paula da Rosa POSSEBON(a) Fernanda FAOT ${ }^{(b)}$ \\ Raissa Micaella Marcello MACHADO(c) \\ Gustavo Giacomelli NASCIMENTO(d) Fábio Renato Manzolli LEITE(d)}

\footnotetext{
(a) Universidade Federal de Pelotas - UFPel, School of Dentistry, Program in Dentistry, Pelotas, RS, Brazil.

(b) Universidade Federal de Pelotas - UFPel, School of Dentistry, Department of Restorative Dentistry, Pelotas, RS, Brazil.

(c) Universidade Estadual de Campinas Unicamp, Piracicaba Dental School,Program in Dentistry, Piracicaba, SP, Brazil.

(d) Aarhus University, Department of Dentistry and Oral Surgery, Denmark.
}

Declaration of Interest: The authors certify that they have no commercial or associative interest that represents a conflict of interest in connection with the manuscript.

\section{Corresponding Author:}

Anna Paula da Rosa Possebon

E-mail: ap.possebon@gmail.com

https://doi.org/10.1590/1807-3107bor-2018.vol32.0111

Submitted: May 16, 2018

Accepted for publication: September 02, 2018

Last revision: September 11, 2018
Abstract: Several instruments have been used to measure oral healthrelated quality of life (OHRQoL). The Oral Health Impact Profile (OHIP) questionnaire was based on the concept that sequential events related to oral diseases can cause discomfort, functional limitations and consequently, result in dysfunctions and even disabilities. There are few studies in the literature that structurally analyze the instruments to verify whether they measure the requirements to which they were designed to. The objective of the study was to evaluate the internal structure of the OHIP-Edent questionnaire. The OHIP-Edent was administered to 54 edentulous patients' wearers of conventional complete dentures. For structural analysis, an exploratory factorial analysis (EFA) was carried out. After determining the internal consistency of the model (Cronbach's alpha $=0.88$ ), the fit was checked using the root mean square error approach (value 0.04), the comparative fit index (value 0.982) and the Tucker-Lewis index (value 0.976). After analysis of the 19 questions and the seven domains proposed in the OHIP-Edent questionnaire, the hypothetical factorial model showed three dimensions denominated "Physical Impact", "Psychological Impact" and "Social Impact". In this sample of conventional complete denture wearers, the OHIP-Edent seems adequate to measure the "Physical Impact", "Psychological Impact", and "Social Impact" of the OHRQoL. The confirmatory factorial analysis confirmed the model and, through adjustment indexes, it was verified that the three dimensions have convergence and consistence adequate in order to characterize the OHRQoL construct with validity.

Keywords: Denture, Complete; Factor Analysis, Statistical; Quality of Life; Oral Health.

\section{Introduction}

Several instruments and tools have been used in order to measure oral health related quality of life (OHRQoL). Among them, it is possible to name the Oral Impacts on Daily Performances (OIDP), Dental Impacts on Daily Living (DIDL), Geriatric Oral Health Assessment Index (GOHAI), and Oral Health Impact Profile (OHIP)., ${ }^{1,2,3,4,5,6}$ The OHIP was developed ${ }^{4}$ through a health conceptual model proposed by Locker.7 That model presumes that sequential events related to oral diseases can cause discomfort, functional limitations, and, consequently, result in dysfunctions and even 
disabilities. That concept allowed a fundamental change in dentistry, since it emphasizes a model of health care through the patient's perspective instead of the professional's. ${ }^{6}$ The original instrument is composed by 49 questions grouped in seven different domains: functional limitation, physical pain, physical limitation, psychological discomfort, social limitation, and disabilities (handicap). Some shorter or population specific versions were further proposed, such as the OHIP-14 and the OHIP-Edent. The OHIP-14 is a reduced version of the OHIP-49, composed by only 14 questions in order to accelerate the application and acceptance of the survey. However, due to limitations of the OHIP-14, such as the lack of questions that approached the masticatory function, and questions that could measure alterations in the perception of the oral health after the rehabilitation with dentures, a specific instrument aimed toward edentulous individuals was developed. Thus, the OHIP-Edent is composed by 19 questions, maintaining the seven original theoretical domains of the OHIP- $49 .{ }^{8}$

It is well known that the meaning of health and quality of life (QOL) can vary according to the social, cultural, political, and practical contexts. Besides that, the concept of QOL considers the individual perception, according to their culture, value system, objectives, expectations, patterns, and worries. ${ }^{9}$ Thus, the instrument, when developed and validated in order to measure a specific construct, is created for specific populations. ${ }^{10}$ Consequently, the questionnaire may not show the gravity and importance of the events through individual's self-perception in a different population, therefore, making it important to analyze the structure and validity of those instruments. ${ }^{11}$

According to Baker et al., ${ }^{6}$ there are many studies on the validity and reliability of those instruments, but it is known that without a structural analysis, it is hard to know for sure if the instrument is adequate for the populations in question and if it really measures what it proposes to in its main objective. Thus, when researchers use specific instrument in order to measure a specific construct, they presuppose that it is receiving and calculating the information for a determined population. Nevertheless, without a structural analysis of the survey, such thought can be invalid. ${ }^{6,12}$ Even with the structural analysis being an essential aspect in studies that investigate OHRQOL, few of them scrutinize structurally if the instruments are really reading all the desired domains. ${ }^{12,13}$ Thus, this study aimed to evaluate the internal structure of OHIP-Edent and to confirm the hypothetical factorial model proposed when the instrument was developed.

\section{Methodology}

\section{Study design}

The study was approved by the Local Research Ethics Committee from the School of Dentistry of the Federal University of Pelotas, approval number 06/2013. To be eligible to participate in the study, volunteers should be fully edentulous, need a pair of conventional complete dentures, and be available to attend follow-up appointments after prostheses installation. The sample size calculation was based on the Berretin-Felix et al. ${ }^{14}$ study, considering the values for the "Social relations" domain (population mean 66.6, expected mean after the denture installation 75.0, standard deviation for the population 15.5, alpha 0.05 , and a power of 0.80 ). The total required number of participants was 50. To avoid the loss of participants, $20 \%$ was added to the sample number. Sixty individuals that needed conventional complete denture were invited to participate in this study, and from those, 54 volunteers have accepted. All volunteers were rehabilitated between 2015 and 2016, with a new pair of conventional complete dentures, which were performed with thermo-polymerizable acrylic resin (TDV, Pomerode, Brazil), artificial acrylic resin teeth (Trilux, Pirassununga, Brazil) and assembled in balanced bilateral occlusion. The complete denture confection was supervised by specialized dentists in prosthodontic. All volunteers were invited to sign an agreement consent.

OHRQOL data were obtained through an interview with the OHIP-Edent instrument. ${ }^{8}$ The OHIP-Edent is composed by 19 questions grouped into seven domains: Functional Limitation (3 questions); Physical Pain (4 questions); Psychological Discomfort (2 questions); Physical Disability (3 questions); Psychological Disability (2 questions); Social Disability (3 questions); Handicap (2 questions). Participants had three possible 
answers for each question of the instrument: (0) never; (1) sometimes; (2) often. For results interpretation, the scores of each domain were summed and further analyzed. The questionnaire was applied three months after the rehabilitation of the 54 patients with conventional complete dentures and after all adjustments need for the adaptation to their new condition. During this evaluation period, there was not participants loss. Data from patients' records and from the OHIP-Edent were typed in duplicate.

\section{Statistical analysis}

All analyses were carried out in the software Stata 14.0 (College Station, US). Sociodemographic data (sex, age, marital status, schooling, income, profession, and edentulism time for the maxilla and mandible in years) were analyzed through descriptive statistics including the mean, standard deviation, and relative frequency. Further statistical analysis was first composed by the exploratory factorial analysis (EFA) in order to determine the latent variables and subjacent to the observed variables for the group data of the instrument. A preliminary Kaizer-Meyer-Olkin (KMO) test was conducted in order to verify the adequacy of the sample for the EFA to be made. Values above 0.5 were considered as subject to factorial analysis. ${ }^{15}$ Through the breakdown of the polychoric correlation matrix through the main factors method, the factor extraction was conducted. In order to retain them, the Kaizer (eigenvalues $>1$ ) method was used. For the rotation method, the Promax oblique rotation was selected. ${ }^{16}$ In order to analyze the internal reliability of the factorial model a Cronbach's alpha coefficient was determined. Values above 0.7 show a factorial structure with good internal consistency to proceed with analysis. ${ }^{17}$

To confirm the hypothetical factorial model found in the EFA, a confirmatory factorial analysis (CFA) was conducted. A path diagram was built to specify the factored model. For parameter setting, the maximum likelihood method was used and standardized coefficients reported. Following that, different adjust indicators were used to evaluate the factorial method. For an acceptable adjustment, the Root Mean Square Error of Approximation (RMSEA), the Comparative Fit Index (CFI) and the Tucker-Lewis index (TLI) were used. The Root Mean Square Error of
Approximation (RMSEA) was used to demonstrate how well the factorial model could reproduce the sample covariance matrix, and values smaller or equal to 0.06 show a good adjustment. Finally, the Comparative Fit Index (CFI) and the Tucker-Lewis index (TLI) were used to compare the predicted and sample matrixes. For both indexes, for a better adjustment the values must be greater or equal to $0.95 .^{18}$

\section{Results}

\section{Sample description}

The sample population consisted of 54 patients, and the majority was female (74.1\%). The mean age was 66.1 years (SD 8.7 years) with $78.2 \%$ of them above 60 years of age. Besides that, 34 of them were married (63.0\%) and 51.9\% were retired. Approximately $68.0 \%$ of the sample received minimum wage and $20.3 \%$ received 2 minimum wages. In addition, $51.8 \%$ studied for less than eight years during schooling age. When asked about how much time they were edentulous, the average was of 29.4 years (SD 12.5 years) for the maxilla and 24.1 years (SD 13.0 years) for the mandible.

\section{Exploratory factorial analysis}

Table 1 summarizes the eigenvalues, variance percentage and $\mathrm{KMO}$ of the exploratory factorial analysis. After the decomposition of the polychoric correlation matrix through the main factors method, the factor extraction was made through the retention criteria of the Kaizer factor. The 19 questions were retained in three factors or domains with eigenvalues above 1.0. While the unrotated model explained 83.4\% of the total variance, Promax rotated model fully explained the variance of the instrument.

Table 2 shows the factorial charges after the Promax rotation. Factor 1 was dubbed as "Physical Impact", factor 2 as "Psychological Impact", and factor 3 as "Social Impact". The factorial charges ranged from 0.32 to 0.96 . The "Physical Impact" factor combined questions that approached mastication, pain/discomfort, and conventional complete denture adaptation. The factor named "Psychological Impact" grouped questions from the limitation and psychological discomfort domains for conventional complete denture wearers, and, 
finally, the "Social Impact" factor gathered questions from the social limitation and disability domains. Thus, from the seven original domains after the exploratory factorial analysis, a hypothetical model was obtained with three main factors. Lastly, the Cronbach's Alpha test revealed a value of 0.88 for the entire instrument, 0.87 for the "Physical Impact"; 0.74 for the "Psychological Impact", and 0.83 for the "Social Impact".

\section{Confirmatory factorial analysis}

Figure shows the path diagram for the factored hypothetical model, created through the EFA. The CFA shows a hypothetical model with three factors for the OHIP-Edent. The root mean squared error approach (RMSEA) value for the described model was 0.04. In addition, Comparative fit index (CFI) and Tucker-Lewis index (TLI) values were 0.982 and 0.976 , respectively.

Table 1. Description of the factors retained by the Kaizer method from the scores obtained by applying the OHIP-Edent (eigenvalue $>1.0)$.

\begin{tabular}{lccc}
\hline Factor & Eigenvalues & Unrotated (\% variance) & Promax rotated (\% variance) \\
\hline 1 & 5.75 & 46.6 & 41.5 \\
2 & 3.22 & 26.0 & 30.0 \\
3 & 1.34 & 10.8 & 28.5 \\
Total variance (\%) & & 83.4 & 100.0 \\
$\mathrm{KMO}$ & & & 0.76 \\
\hline
\end{tabular}

Table 2. Factor charges after rotation of Promax factors.

\begin{tabular}{|c|c|c|c|}
\hline Observed variables & $\begin{array}{c}\text { Factor 1: } \\
\text { Physical impact }\end{array}$ & $\begin{array}{c}\text { Factor 2: } \\
\text { Psychological impact }\end{array}$ & $\begin{array}{c}\text { Factor 3: } \\
\text { Social impact }\end{array}$ \\
\hline 1- Chewing difficulty & 0.5754 & 0.0097 & 0.1471 \\
\hline 2- Food catching & 0.3301 & -0.0153 & 0.1404 \\
\hline 3- Dentures not fitting & 0.4995 & 0.1828 & -0.0382 \\
\hline 4- Aching sensation & 0.6875 & -0.2483 & 0.2282 \\
\hline 5- Discomfort during eating & 0.8517 & 0.0311 & 0.0640 \\
\hline 6- Sore spots & 0.7960 & -0.1099 & -0.2119 \\
\hline 7- Uncomfortable dentures & 0.4050 & 0.3736 & -0.0289 \\
\hline 8- Worried & 0.0199 & 0.7968 & -0.0339 \\
\hline 9- Self-conscious & -0.1806 & 0.7279 & 0.1350 \\
\hline 10- Avoids eating & 0.6586 & 0.1028 & -0.2088 \\
\hline 11 - Unable to eat & 0.7455 & 0.1525 & 0.0003 \\
\hline 12- Interrupts meals & 0.4685 & 0.4507 & -0.0562 \\
\hline 13- Upset & 0.1701 & 0.7432 & -0.0993 \\
\hline 14- Embarrassed & 0.1132 & 0.3187 & 0.0790 \\
\hline 15- Avoided going out & 0.0423 & -0.0070 & 0.7482 \\
\hline 16- Less tolerant & 0.0405 & -0.2006 & 0.8932 \\
\hline 17- Irritable & -0.2113 & 0.1038 & 0.8341 \\
\hline 18- Unable to enjoy other people's company & -0.0074 & 0.0361 & 0.9535 \\
\hline 19- Life in general less satisfying & 0.2810 & 0.1936 & 0.4485 \\
\hline
\end{tabular}

The strongest associations between questions and domains are marked in bold. 


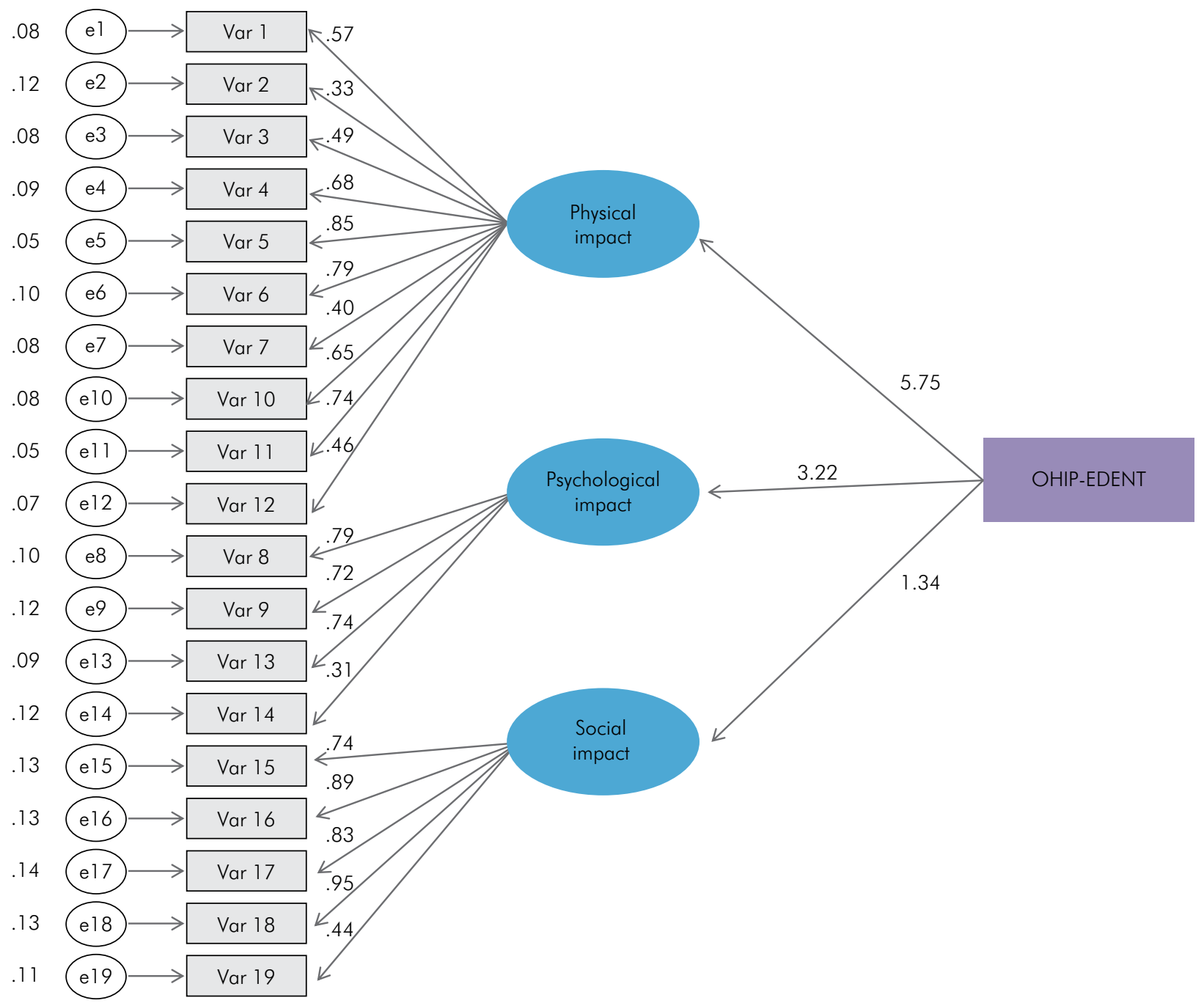

Figure. Path diagram of the hypothetical factorial model for OHIP-Edent in the sample population

\section{Discussion}

To the best of the authors' knowledge, the present study was the first one to perform the confirmatory factorial analysis for the OHIP-Edent instrument in order to confirm a hypothetical factorial model. The KMO test indicated satisfactory sample size for the factorial analysis and the Cronbach's alpha test reinforced the proper internal consistency of the questionnaire and of each of the three identified domains. ${ }^{17}$ The CFA showed an adequate model fit for the hypothetical model of OHIP-Edent, as all fit parameters presented satisfactory values. ${ }^{18}$ Therefore, the results of the present study suggest that the OHIPEdent should be grouped in three domains ("Physical
Impact", "Psychological Impact", and "Social Impact") instead of the seven originally proposed. Besides, our results suggest that those three factors present satisfactory explanation of the OHRQoL construct.

Evidence suggests that the OHRQoL is multidimensional and includes physical, psychological and social dimensions. ${ }^{19,20,21}$ The OHIP was developed in order to offer measurements for self-reported dysfunction, discomfort and disabilities imputed to the oral condition. ${ }^{4}$ Following the original description, the OHIP-Edent was built to maintain all seven domains from the OHIP-49 based on specialist's opinions, ${ }^{7,8}$ however, our study suggests the presence of three domains instead. The first domain, labeled "Physical Impact", grouped the 10 original questions for the 
functional limitation, physical pain and physical limitation domains from the OHIP-Edent. It seems that those questions measured one unique subjective aspect for the oral condition for health perception, which refers to a physical impact associated to the use of conventional complete dentures. The "Physical Impact" domain was the one with the highest eigenvalue among the three domains identified. Hence, it provides evidence that most of the variance of the instrument is related to the presence of physical symptoms. It reinforces the importance of measuring the "Physical Impact" of the tooth loss on the perception of oral health. Previous studies analyzed the internal structure of the instrument that measure OHRQoL; however, the authors could not find a single "Physical Impact" domain, as we did. ${ }^{19,22}$ Souza et al. ${ }^{22}$ reported that the "Physical Impact" domain should be subdivided into "Masticatory Complaints" and "Oral Pain/ Discomfort". Furthermore, instead of including a question about the interruption of meals in the "Physical Impact" domain, the authors included it under the "Psychological Discomfort". Our results revealed that those questions converged to the same domain, going in the opposite direction of the findings of Souza et al. ${ }^{22}$ Pain may physically limit people to wear dentures, and it is directly related to the mastication, as masticatory problems due to painful symptomatology caused by the use of conventional complete dentures are common findings. ${ }^{8,23}$ Baker et al. ${ }^{6}$ found that functional limitations were related to pain experiences, which are aligned with our findings.

It is known that questions related to psychological aspects impact on both the perception of health and on the quality of life of individuals. ${ }^{22}$ Thus, it is not surprising that in the present study only one dimension related to psychological aspects was found, instead of the two domains originally proposed in the instrument. According to some researchers, ${ }^{24,25,26}$ even individuals that are easily adapted to conventional complete dentures show some emotional impairment due to complete tooth loss. In most cases, there is difficulty to accept the current oral condition, which in many cases, affects the individuals' self-confidence. The original questions from the psychological limitation and discomfort domains from the OHIP-Edent approach emotional themes related to the use of conventional complete dentures by edentulous individuals. Souza et al., ${ }^{22}$ also discovered a "Psychological domain" with a single dimension, separated from the others. However, as mentioned before, the question about the interruption of meals was included in the "Psychological domain". The authors believed that meal interruptions were more associated to psychological and emotional factors related to the use of conventional complete denture than to physical factors. On the other hand, the present study showed that meal interruptions are actually more related to the physical impact caused by dentures, such as pain/discomfort, and inadequate dentures settling, which physically impair individuals, as they compromise their mastication. ${ }^{23}$ Furthermore, according to Carlsson, ${ }^{27}$ psychological factors are much more related to complete dentures acceptance than to its quality. It corroborates our findings since "Psychological Impact" domain comprised only questions related to the emotion impairments of wearing conventional complete dentures.

Completely edentulous individuals face social deficiencies, which can even result in social isolation. ${ }^{7,26}$ Thus, the identification of a single "Social Impact" domain, which groups questions of social limitations and disabilities, reinforces the impact of edentulism on social aspects of life. John et al. and Montero et al., ${ }^{12,28}$ who analyzed the OHIP-49 and OHIP-14 versions respectively, found out a domain called psychosocial, which combines the social and psychological original domains in a single dimension. Even though social and psychological aspects seem to be correlated, they measure different components of quality of life. Therefore, the combination of those aspects into one domain may lead to loss of information on the real impact of oral conditions on both social and psychological aspects of the individual's quality of life.

There is only one study in the literature that evaluated the internal consistency of OHIP-Edent. ${ }^{22}$ However, as aforementioned, our results do not completely confirm the findings from the previous article. It is possible that the controversy between results relates to the different rehabilitation treatments. While Souza et al. ${ }^{22}$ used both conventional and implant-supported dentures, our study focused only on conventional complete dentures. As known, individuals rehabilitated with implant- 
supported dentures have different complains and this fact may explain the divergent results.

An important point that may be highlighted in this study is the homogeneity of the sample, regarding the rehabilitation treatment, the income and the educational level of the individuals. Those points are relevant for the factorial analysis, since participants must have a similar profile for a more accurate determination of domains in a specific construct. Inclusion of confounding bias in the sample can influence the grouping questions and the model determination. One limitation of the present study may be related to the generalization and extrapolation of the results toward other populations, since the points that analyzed the internal structure of the instrument were directly influenced from the

\section{References}

1. Abegg C, Fontanive VN, Tsakos G, Davoglio RS, Oliveira MM. Adapting and testing the oral impacts on daily performances among adults and elderly in Brazil. Gerodontology. 2015 Mar;32(1):46-52. https://doi.org/10.1111/ger.12051

2. Leao A, Sheiham A. The development of a socio-dental measure of dental impacts on daily living. Community Dent Health. 1996 Mar;13(1):22-6.

3. Atchison KA, Dolan TA. Development of the Geriatric Oral Health Assessment Index. J Dent Educ. 1990 Nov;54(11):680-7.

4. Slade GD, Spencer AJ. Development and evaluation of the Oral Health Impact Profile. Community Dent Health. 1994 Mar;11(1):3-11.

5. Brennan DS, Spencer AJ. Comparison of a generic and a specific measure of oral health related quality of life. Community Dent Health. 2005 Mar;22(1):11-8.

6. Baker SR, Gibson B, Locker D. Is the oral health impact profile measuring up? Investigating the scale's construct validity using structural equation modelling. Community Dent Oral Epidemiol. 2008 Dec;36(6):532-41. https://doi.org/10.1111/j.1600-0528.2008.00440.x

7. Locker D. Measuring oral health: a conceptual framework. Community Dent Health. 1988 Mar;5(1):3-18.

8. Allen F, Locker D. A modified short version of the oral health impact profile for assessing health-related quality of life in edentulous adults. Int J Prosthodont. 2002 Sep-Oct; 15(5):446-50.

9. The World Health Organization Quality of Life assessment (WHOQOL): position paper from the World Health Organization. Soc Sci Med. 1995 Nov;41(10):1403-9. https://doi.org/10.1016/0277-9536(95)00112-K sample characteristics. However, it can be useful as a basis for future researches that aim to use instruments to measure OHRQoL.

\section{Conclusion}

Taken together, our findings suggest OHRQoL can be measured with the OHIP-Edent. In this sample of Brazilian edentulous, the OHIP-Edent measured three dimensions of OHRQoL: "Physical Impact", "Psychological Impact", and "Social Impact". Confirmatory factor analysis confirmed the threefactors-model in terms of convergence and consistency to characterize adequately the OHRQoL construct with validity.

10. Fleck MP, Louzada S, Xavier M, Chachamovich E, Vieira $G$, Santos L et al. [Application of the Portuguese version of the abbreviated instrument of quality life WHOQOL-bref]. Rev Saúde Pública. 2000 Apr;34(2):178-83. Portuguese. https://doi.org/10.1590/S0034-89102000000200012

11. Locker D, Allen F. What do measures of 'oral health-related quality of life' measure? Community Dent Oral Epidemiol. $2007 \mathrm{Dec} ; 35(6): 401-11$. https://doi.org/10.1111/j.1600-0528.2007.00418.x

12. John MT, Reissmann DR, Feverstahler L, Waller N, Baba K, Larsson $\mathrm{P}$ et al. Exploratory factor analysis of the Oral Health Impact Profile. J Oral Rehabil. 2014 Sep;41(9):635-43. https://doi.org/10.1111/joor.12192PMID:24909881

13. Souza RF, Patrocínio L, Pero AC, Marra J, Compagnoni MA. Reliability and validation of a Brazilian version of the Oral Health Impact Profile for assessing edentulous subjects. J Oral Rehabil. 2007 Nov;34(11):821-6. https://doi.org/10.1111/i.1365-2842.2007.01749.x

14. Berretin-Felix G, Nary Filho H, Padovani CR, Machado WM. A longitudinal study of quality of life of elderly with mandibular implant-supported fixed prostheses. Clin Oral Implants Res. 2008 Jul;19(7):704-8. https://doi.org/10.1111/j.1600-0501.2007.01451.x

15. Hair JF, Black WC, Babin JB, Anderson RE. Multivariate data analysis. Upper Saddle River: Pearson Prentice Hall; 2010.

16. Schimitt TA, Sass DA. Rotation criteria and hypothesis testing for exploratory factor analysis: implications for factor pattern loadings and interfactor correlations. Educ Psychol Meas. 2011;71(1):95-113. https://doi.org/10.1177/0013164410387348 
17. George D, Mallery P. SPSS for Windows step by step: A simple guide and reference. Boston: Allyn \& Bacon; 2003.

18. Brown TA. Confirmatory factor analysis for applied research. New York: Guilford; 2006.

19. John MT. Exploring dimensions of oral health-related quality of life using experts' opinions. Qual Life Res. 2007 May; 16(4):697704. https://doi.org/10.1007/s11136-006-9150-8

20. Santos CM, Oliveira BH, Nadanovsky P, Hilgert JB, Celeste RK, Hugo FN. The Oral Health Impact Profile-14: a unidimensional scale? Cad Saúde Pública. 2013 Apr;29(4):749-57. https://doi.org/10.1590/S0102-311X2013000800012

21. Sischo L, Broder HL. Oral health-related quality of life: what, why, how, and future implications. J Dent Res. 2011 Nov;90(11):1264-70. https://doi.org/10.1177/0022034511399918

22. Souza RF, Leles CR, Guyatt GH, Pontes CB, Della Vecchia MP, Neves FD. Exploratory factor analysis of the Brazilian OHIP for edentulous subjects. J Oral Rehabil. 2010 Mar;37(3):202-8. https://doi.org/10.1111/j.1365-2842.2009.02043.x

23. Sebring NG, Guckes AD, Li SH, McCarthy GR. Nutritional adequacy of reported intake of edentulous subjects treated with new conventional or implant-supported mandibular dentures. J Prosthet Dent. 1995 Oct;74(4):358-63. https://doi.org/10.1016/S0022-3913(05)80374-9

24. Polzer I, Schimmel M, Müller F, Biffar R. Edentulism as part of the general health problems of elderly adults. Int Dent J. 2010 Jun;60(3):143-55. https://doi.org/10.1922/IDJ_2184Polzer13

25. Fiske J, Davis DM, Frances C, Gelbier S. The emotional effects of tooth loss in edentulous people. Br Dent J. 1998 Jan;184(2):90-3. https://doi.org/10.1038/sj.bdj.4809551

26. Scott BJ, Leung KC, McMillan AS, Davis DM, Fiske J. A transcultural perspective on the emotional effect of tooth loss in complete denture wearers. Int J Prosthodont. 2001 SepOct;14(5):461-5.

27. Carlsson GE. Clinical morbidity and sequelae of treatment with complete dentures. J Prosthet Dent. 1998 Jan;79(1):17 23. https://doi.org/10.1016/S0022-3913(98)70188-X

28. Montero J, Bravo M, Vicente MP, Galindo MP, López $J F$, Albaladejo A. Dimensional structure of the oral health-related quality of life in healthy Spanish workers. Health Qual Life Outcomes. 2010 Feb;8(1):24. https://doi.org/10.1186/1477-7525-8-24 